\title{
Debate político-eleitoral no Facebook: os comentários do público em posts jornalísticos na eleição presidencial de 2014
}

\author{
Isabele Batista Mitozo \\ Michele Goulart Massuchin \\ Fernanda Cavassana de Carvalho
}

\section{Introdução ${ }^{1}$}

As plataformas digitais têm proporcionado novas formas tanto de produção quanto de recepção de conteúdo, principalmente por meio das redes sociais. Da mesma maneira que o público está presente na internet, as grandes empresas de comunicação também ocuparam esse espaço como forma de aproximarem-se de seus leitores, propiciando novos ambientes de interação. Além de produzirem conteúdo em seus portais, os jornais brasileiros estão ativos nas redes sociais digitais, como no Facebook, o que torna possível ao leitor que acessa essas ferramentas acompanhar perfis institucionais jornalísticos e, ainda, utilizar o espaço destinado aos comentários.

Por se tratar de redes de relacionamento, essas páginas dão acesso não só ao conteúdo jornalístico veiculado, mas também àquele produzido por outros usuários que interagem com as publicações e com outros perfis. Sabendo que os temas e os conteúdos veiculados pela mídia podem ter efeitos na agenda do debate público (McCombs, 2009), os comentários nos posts dessas páginas representam um objeto importante a ser analisado.

Durante o período eleitoral, a arena política passa a ser um dos temas centrais das empresas de comunicação, ganhando destaque no debate público e, assim, se tornando um alvo mais tangível a elogios e críticas da audiência. Nesse contexto, o advento da internet como uma "extensão da esfera pública" (Dahlberg, 2001) pode trazer, aos debates desenvolvidos nesse ambiente, características da deliberação offline, tais como a reciprocidade, i.e., a disponibilidade dos interlocutores para reagir de alguma forma ao argumento alheio (Dahlberg, 2004).

Considerando esses pressupostos teóricos, o artigo tem por objetivo identificar as características do debate político-eleitoral entre cidadãos nas postagens acerca da eleição presidencial de 2014 das páginas oficiais de jornais brasileiros no Facebook. A escolha dessa rede social online se dá por ser aquela mais utilizada pelos brasileiros (Brasil, 2014) e pela atuante presença da imprensa convencional nela.

\footnotetext{
1 Uma versão prévia deste artigo foi apresentada durante o VI Congresso da Associação Brasileira de Pesquisadores em Comunicação e Política (VI Compolítica), em 2015. Agradecemos pelas sugestões e críticas apontadas durante o debate.
} 
DEBATE POLÍTICO-ELEITORAL NO FACEBOOK

São unidades de análise deste artigo os comentários feitos aos posts das páginas dos três principais quality papers de abrangência nacional: Folha de S. Paulo (SP), O Globo (RJ) e O Estado de S. Paulo (SP). A análise considera o total de 610.660 comentários que citavam, ao menos, um dos três principais candidatos à presidência do Brasil em 2014 Aécio Neves (PSDB), Dilma Rousseff (PT) e Marina Silva/Eduardo Campos (PSB) - durante a campanha eleitoral, feitos às 14.794 postagens que também faziam referência aos candidatos.

O banco de dados utilizado aqui identifica uma série de variáveis, dentre as quais este artigo seleciona aquelas ligadas ao debate público, para análise: 1) a posição do comentador: se ele é monológico ou dialógico/recíproco, i.e., se ele demonstra ler os demais comentários (Dahlberg, 2004); 2) o tipo de justificativa que o comentador expressa; e 3) a reflexividade do comentário, ou seja, se o usuário da rede social tentou persuadir, progredir ou radicalizar o debate (Jensen, 2003a).

A partir dos dados, trabalha-se com duas hipóteses: 1) apesar de as redes sociais terem ampliado o acesso à discussão eleitoral, o debate online em comentários de publicações jornalísticas no Facebook, especialmente, afasta-se de um debate deliberativo normativo, possuindo características menos rígidas nas ocorrências de reciprocidade e progresso, pelo próprio fato de o espaço em que se desenvolve a discussão não ser político em si; 2) esse fato, contudo, não afasta a possibilidade de os comentadores usarem o Facebook para dialogar a fim de persuadirem outros em relação a sua posição política. As análises, portanto, concentram-se em identificar diferenças e semelhanças entre o debate gerado pelos posts dos referidos jornais nacionais e as características qualitativas desse debate online durante a eleição presidencial.

O artigo traz, na próxima seção, "Plataforma digital, participação online e debate público", uma discussão teórica sobre o debate público online e as possibilidades e limitações já apontadas pela literatura sobre o tema. Na sequência, em "Metodologia e análise dos dados: o debate político-eleitoral nas páginas de jornais brasileiros no Facebook", detalham-se as variáveis e categorias utilizadas na pesquisa. É apresentado um panorama geral dessas características a partir do volume de comentários por posts ao longo do período. E, em "Considerações finais", é finalmente realizada a análise, discutindo-se o que caracterizou o debate, tendo em vista: 1) o caráter monológico ou recíproco dos comentários; 2) a justificativa que apresentam; e 3) a reflexividade que expressam. Por fim, são feitas algumas considerações sobre os achados da pesquisa.

\section{Plataforma digital, participação online e debate público}

A comunicação online possui características que a diferenciam daquela mediada pelos meios de comunicação de massa em suportes tradicionais. A interatividade, e a consequente possibilidade de debate entre cidadãos, é uma delas. Ao ingressar nas páginas de periódicos no Facebook, por exemplo, é possível travar discussões momentâneas com outros usuários da rede sobre temas de interesse público, especialmente político-eleitorais. 
ISABELE BATISTA MITOZO; MICHELE GOULART MASSUCHIN; FERNANDA CAVASSANA DE CARVALHO

Na perspectiva de Dahlberg (2001), o ciberespaço é uma extensão da esfera pública, considerada por Habermas (2003, p. 45) como a "forma primeira de uma nova sociedade", constituída a partir dos debates políticos que passaram a se desenvolver nos cafés burgueses, quando os private men adentraram a arena da discussão política, i.e. passaram a ter a política como pauta nessa esfera literária burguesa, que se tornaria Parlamento, em que aqueles cidadãos passariam ao patamar de common men (Habermas, 2003). A internet, por sua vez, contribuiria com a prática democrática na medida em que é possível expandir o debate público, o que é corroborado por autores como Strandberg e Berg (2013), que acrescentam a ideia de que a internet seria um minipúblico.

As experiências de participação e interação na plataforma digital ocorrem de diversas maneiras: por meio de comunidades, chats online, páginas independentes, entre outras formas que variam desde perspectivas com enfoque na criação de comunidades até ações individualistas (Dahlberg, 2001). No entanto, isso não é suficiente para fortalecer a democracia, porque um dos pressupostos para tal, conforme as teorias participativa e deliberativa, é a presença de um discurso crítico racional, o que necessita de outros espaços de comunicação que não fiquem restritos a grupos específicos nem a ações individuais, em que haja possibilidade de debate nos moldes do que ocorre na esfera pública offline.

Dahlgren (2005) cita alguns espaços já existentes na internet que possibilitam exemplificar extensões da esfera pública, como sites governamentais interativos (eGovernment), sites de ativistas para gerar intervenções políticas, fóruns online e a presença de empresas jornalísticas que interagem com os leitores por meio dessa plataforma.

Com a multiplicação desses espaços na internet, os veículos tradicionais da imprensa buscaram modos de se adaptar ao novo cenário. Os jornais impressos, por exemplo, criaram portais de notícias e têm utilizado as redes sociais para propagar conteúdos previamente definidos que, com essa ação, ganham destaque e visibilidade, e circulam mais. Na concepção de Zago (2012), as redes sociais podem ser consideradas ferramentas de reprodução e circulação de material informativo. Além disso, o conteúdo que circularia apenas nos portais e nas edições impressas passa a chegar a várias subredes (Recuero, 2009) por meio de mecanismos como curtir e compartilhar, oferecidos pelo Facebook. Essas possibilidades, reiteram Zago e Bastos (2013), conferem maior visibilidade às notícias.

Outros autores que também perpassam essa discussão sobre a circulação de informação pelas redes sociais são Aggio e Reis (2015), chamando esse fenômeno de ecologia dos fluxos de informação online. As notícias que são postadas no site ganham um link no Facebook e, na medida em que a informação ganha mais visibilidade, atrai o público para visitar o website. Por outro lado, além de dar maior visibilidade ao conteúdo que se destaca nas redes sociais, esses espaços permitem ainda uma aproximação mais evidente entre leitores e produtores das notícias, criando um lugar propício ao debate. Por meio dos comentários, é possível identificar opiniões, gostos, interesses e posicionamentos do 
DEBATE POLÍTICO-ELEITORAL NO FACEBOOK

público que antes só chegavam à versão impressa dos jornais por meio da carta dos leitores ou por telefone. Logo, os meios de comunicação foram atraídos pela internet, deram mais visibilidade a sua produção de notícias e também passaram a usufruir da interatividade.

Janssen e Kies (2004) consideram as possibilidades interativas da internet como implicações democráticas, havendo diferenças significativas em relação aos meios tradicionais de comunicação, pois, além da presença de informação, existe no ambiente online um espaço distinto de debate que, segundo os autores, é menos centralizado, mais aberto, sem limitação geográfica e temporal, assim como permite maior liberdade dos cidadãos para expressarem suas opiniões.

Ao observar os comentários nas redes sociais - tal como este artigo se propõe a fazer -, considera-se que eles compõem uma rede de opiniões e conteúdos que as pessoas compartilham de maneira voluntária, em que se criam laços ou afinidades a partir da ação de responder e da troca de conteúdo (Wasko e Faraj, 2005), principalmente, quando há interesses comuns com determinados temas, como é o caso de política e, mais especificamente, eleições. Além disso, segundo Dahlgren (2005), a interação por meio da plataforma digital ocorre em dois níveis: entre os usuários e os meios de comunicação/conteúdo e também entre os próprios usuários, criando uma conversação.

Para olhar para o debate que ocorre nos meios digitais, alguns pressupostos da teoria habermasiana de deliberação são adaptados. Parte-se, então, de uma flexibilização que o próprio Habermas já reconhecera em sua proposta analítica: os critérios bastante fechados e ideais de um debate deliberativo, tais como discussão racional desprovida de julgamento prévio dos indivíduos e, por meio desse e de outros procedimentos, estabelecimento de um consenso.

Desse modo, essas adaptações e alguns acréscimos foram realizados, a fim de tornar esse modelo mais realista e sanar as críticas, especialmente aquelas voltadas ao consenso como indicativo de que o debate público não surgiria para promover o encontro de cidadãos, mas sim uma reunião de like-minded people, i.e., pessoas que pensam da mesma forma sobre o assunto (Sanders, 1997; Miguel, 2002). Os pressupostos teóricos, mais adiante, foram transformados em indicadores analíticos por Dahlberg $(2001,2004)$, Jensen (2003a), Janssen e Kies (2004), dentre outros, que discutem formas de analisar o debate online. Tais modelos foram utilizados neste artigo assim como em outros trabalhos que analisam experiências de debate na rede social no Brasil, como Sampaio, Maia e Marques (2010), Penteado e Avanzi (2013), Sampaio e Barros (2010) e Cervi (2013).

O estudo de Jensen (2003a), por exemplo, observou diferentes possibilidades de debate, comparando um espaço oferecido por iniciativa governamental e outro "anárquico", investigando qual deles se aproximaria mais de uma esfera pública online. Os resultados indicaram que o espaço oferecido pelo governo - o portal nordpol.dk - teve mais qualidade nos quesitos argumentação e respeito, mas que, de maneira geral, esse debate online é uma atividade composta por uma quantidade de cidadãos restrita, bem educada e politicamente ativa (Jensen, 2003a), o que não demonstra, de fato, uma ampliação de acesso ao debate público por meio de ferramentas tecnológicas. Segundo o 
ISABELE BATISTA MITOZO; MICHELE GOULART MASSUCHIN; FERNANDA CAVASSANA DE CARVALHO

autor, há regras como a moderação, a identificação geográfica e a presença de políticos que interferem na qualidade do debate gerado pelos espaços online.

No Brasil, já há diversas experiências de debate analisadas, como é o caso dos fóruns online do orçamento participativo digital (OPD) de Belo Horizonte, estudados por Sampaio, Maia e Marques (2010). A conclusão dos autores, por se tratar de um espaço específico de debate, é de que esses ambientes podem oferecer trocas discursivas qualificadas, com altos índices de justificação, respeito e identificação. Sampaio, Maia e Marques (2010) ressaltam que, mesmo que os resultados não apontem para um modelo ideal de deliberação, o OPD trouxe duas contribuições importantes: criou um espaço próprio para discussões sobre o assunto e possibilitou a participação por meio da "expressão da opinião" (Jensen, 2014).

Sampaio e Barros (2010) analisam comentários feitos por leitores a postagens no site da Folha de S. Paulo. Os resultados indicam que houve um alto grau de deliberação, mas, muitas vezes, o objetivo dos participantes era a vitória discursiva e não o entendimento mútuo. Por outro lado, Sampaio e Barros (2010) consideram que a presença de comentários também possui um potencial enriquecimento informativo, na medida em que se acrescentam novas perspectivas e posicionamentos, o que tem relação com as discussões sobre os prossumers, em que os indivíduos tanto consomem quanto produzem informação, algo que sobressai com a web 2.0.

Também observando um ambiente de debate público, Cervi (2013) analisa o conteúdo dos comentários gerados nas notícias sobre eleições no portal de $O$ Estado de $S$. Paulo. Seu principal resultado indica que aqueles comentadores falam entre si e se distanciam do conteúdo das postagens, ganhando autonomia, e que o estímulo aos leitores para promoverem o debate parte da própria quantidade de produção de notícias. Além disso, a discussão tende a apresentar pouca justificativa e serve para reforçar posicionamento.

Com uma discussão mais próxima do objeto a ser analisado neste artigo, Barros e Carreiro (2015) fazem um estudo sobre comentários nas páginas dos três quality papers nacionais no Facebook. Os autores, de forma descritiva, analisam a qualidade da deliberação desenvolvida em 1.164 comentários ligados aos temas "Lei de Cotas", "homofobia", "Lei da Ficha Limpa", "copa do mundo de futebol" e "julgamento do Mensalão". Dentre seus resultados, percebe-se que os participantes raramente são recíprocos e, embora temas com maior dissenso tendam a apresentar maior nível de justificativa "porque as pessoas precisam justificar sua própria posição e argumentar na tentativa de convencimento do outro" (Barros e Carreiro, 2015, p. 180), 57,6\% dos comentários não apresentaram qualquer justificativa.

As diferenças entre as ferramentas de discussão também influenciam o tipo de debate gerado e, consequentemente, as conclusões das pesquisas, segundo cada objeto. O trabalho de Papacharissi (2004), que observou grupos de discussão, concluiu que 85,8\% das participações tratavam de algum tema e dialogavam, e a maioria dos participantes agiam de maneira civilizada. A observação de Sampaio e Barros (2010) sobre páginas dos 
DEBATE POLÍTICO-ELEITORAL NO FACEBOOK

próprios jornais também indicou que os temas em pauta geram diferentes resultados no debate e chamam mais ou menos a atenção dos cidadãos conectados. Além disso, a moderação e a presença de políticos também garantem sucesso no uso das ferramentas (Jensen, 2003b), já que evitam ocorrências graves de desrespeito. Dessa forma, há variáveis inerentes ao ambiente de debate que interferem na forma como ocorrem as discussões.

Assim, partindo dos estudos empíricos desenvolvidos nos últimos anos, já é possível considerar, com mais cautela, as potencialidades do debate enfatizadas na primeira década do século XXI - em uma perspectiva do campo deliberativo - em função das limitações e dos problemas encontrados por alguns autores nesse espaço comunicativo, inclusive o próprio Dahlberg (2001), ao estudar determinados espaços de debate na plataforma digital. Entre as questões que ainda limitam a ampliação do debate estão: as diferenças culturais e sociais que permanecem e são transferidas para a rede (Norris, 2001); a ideia de que a tecnologia sozinha não é capaz de alterar as práticas políticas tradicionais (Dahlberg, 2001); e a existência do risco de grupos não dialogarem com opiniões diferentes e o debate online servir apenas para reforçar posições e opiniões (Sunstein, 2003), criando segmentação de pessoas e espaços de dispersão, e não de deliberação (Dahlgren, 2005).

Com base na discussão teórica inicial sobre as possibilidades oferecidas pela internet para o debate público, na tentativa de aproximação em relação aos requisitos para um modelo normativo, a partir dos resultados apontados por diversos pesquisadores e das limitações já encontradas até então, é mais viável, do ponto de vista analítico, considerar os espaços online pelo viés do engajamento dos cidadãos na campanha eleitoral, com menores exigências acerca dos parâmetros da teoria deliberativa (Jensen, 2014; Strandberg e Berg, 2013).

\section{Metodologia e análise dos dados: o debate político-eleitoral nas páginas de jornais brasileiros no Facebook}

Tendo em vista o que foi apresentado acima, são discutidas neste tópico as questões de ordem metodológica que norteiam a análise dos dados. A metodologia utilizada nesta investigação foi desenvolvida pelo Grupo de Pesquisa em Comunicação Política e Opinião Pública (CPOP), da Universidade Federal do Paraná (UFPR)², com base em modelos previamente utilizados por autores como Dahlberg (2004) e Jensen (2003a) para observar as características do debate que ocorre em espaços online. Assim também, o banco de dados utilizado foi produzido pelo CPOP-UFPR ${ }^{3}$, com a extração dos dados do Facebook realizada semanalmente por meio do aplicativo Netvizz, durante todo o período

\footnotetext{
2 Dentro do projeto de pesquisa intitulado "Opinião Pública e debate político na web", sob coordenação do Prof. Dr. Emerson Urizzi Cervi, líder do grupo.

3 As autoras agradecem a todos os estudantes de graduação e pós-graduação, integrantes do grupo, que atuaram na coleta dos dados.
} 
eleitoral. O processo de codificação dos dados foi realizado manualmente pelo conjunto de pesquisadores do referido grupo.

O corpus a ser analisado a seguir é composto de todos os comentários ${ }^{4}$ que mencionavam diretamente ao menos um dos três principais presidenciáveis (Aécio Neves, Dilma Rousseff e Eduardo Campos/Marina Silva ${ }^{5}$ ) em posts que também faziam tal menção. O período recortado para observação compreende todo o período eleitoral (de 10 de julho a 31 de outubro de 2014), computando 17 semanas em análise. No total, foram 14.794 posts na condição acima apresentada e, dentro desse universo, 610.660 comentários que também faziam referência a algum dos três principais candidatos.

Os jornais que tiveram a página de Facebook analisada foram Folha de S. Paulo, $O$ Estado de S. Paulo e O Globo. Essa escolha se deveu ao fato de, ao observar todo o banco de dados à disposição, constituído de mais nove jornais regionais, perceber-se que $97 \%$ do debate se concentrou nos três referidos veículos nacionais de imprensa, o que indica que seu alcance online segue o impresso ${ }^{6}$.

O objetivo do artigo é identificar de que modo as referidas páginas de Facebook foram utilizadas como espaço para promover o debate entre os usuários da rede social sobre a eleição presidencial de 2014. Para tanto, observam-se de forma específica neste artigo três características do debate: 1) a postura do comentador (monológico ou recíproco) (Dahlberg, 2004; Jensen, 2003a; Sampaio, Maia e Marques, 2010); 2) a justificativa utilizada (Cervi, 2013; Jensen, 2003a); e 3) a reflexividade apresentada no comentário (persuasão, progresso, radicalização) (Jensen, 2003a).

Do mesmo modo que aponta Cervi (2013, p. 81), neste artigo são desconsiderados "os efeitos que os enquadramentos adotados pelo veículo de comunicação [i.e., a abordagem dada aos fatos] têm sobre o volume e o tipo de manifestação dos participantes". Esta análise, apesar de pôr lupa, algumas vezes, sobre os temas em foco nas semanas, não olha para todas as variáveis que a composição verbal dos comentários proporciona avaliar. Isso, por sua vez, fugiria do escopo analítico proposto. Aqui, observase a relação de debate entre os comentadores, i.e., as características do debate público desenvolvido.

A metodologia utilizada é a análise de conteúdo quantitativa, sendo, portanto, analisadas as variáveis e suas respectivas categorias a partir de testes estatísticos, tendo a coleta sido realizada com base em um livro de codificação, previamente elaborado. A

\footnotetext{
${ }^{4}$ Essa análise não leva em consideração e não tem por objetivo diferenciar os comentários feitos por cidadãos daqueles realizados por robôs projetados para fazer comentários. No processo de extração dos dados, o Netvizz não oferece essa informação. A pesquisa apenas pode apresentar um estudo do comportamento dos comentadores, os quais podem ou não se aproximar daquele típico de robôs. Isso pode ser identificado pelos horários anormais de postagens ou pela repetição de frases semelhantes. No entanto, isso não é suficiente para enquadrá-los como feitos por um robô.

5 Devido à mudança de candidatos do PSB em função da morte de Eduardo Campos, a pesquisa considerou exclusivamente as citações desse candidato até o dia 13 de agosto de 2014, sendo que dessa data até 31 de agosto considerou-se a citação tanto de Marina Silva quanto de Eduardo Campos. A partir de $1^{\circ}$ de setembro, consideraram-se apenas as menções à nova candidata.

6 Segundo dados da Associação Nacional de Jornais (2011), a Folha de S. Paulo tem circulação média de 286.398 exemplares, O Estado de S. Paulo, de 263.046, e O Globo possui circulação média de 256.259 exemplares, constituindo-se como os maiores jornais do país (Barros e Carreiro, 2015, p. 177).
} 
DEBATE POLÍTICO-ELEITORAL NO FACEBOOK

intensidade do debate é apresentada, primeiramente, a fim de expor um panorama do fluxo da discussão. Assim, a partir da observação da média de comentários por post em uma escala temporal que contempla todas as semanas em estudo, pode-se observar em que momentos os comentadores produziram mais debate. É realizada, ainda, uma comparação entre os veículos em análise, a fim de perceber as oscilações e tendências existentes em cada um deles. Essa comparação é feita por meio do teste dos resíduos padronizados?

Mais adiante, o artigo se concentra, enfim, na observação de como os comentadores dos veículos nacionais se posicionam no debate. Dahlberg (2004) apresenta o critério de reciprocidade, i.e., se os debatedores estão reagindo de alguma maneira a outros comentários ou se simplesmente postam sua opinião sem acompanhar o que está em discussão entre os demais participantes. Assim como fizeram Sampaio, Maia e Marques (2010), os termos adotados aqui são "recíproco", para o comentário que interage com outro(s), e "monológico", para aqueles em que se "fala sozinho" (Cervi, 2013).

Em seguida, analisa-se o tipo de justificativa expressado em cada comentário, i.e., se os comentadores estão preocupados em apresentar alguma explicação sobre seu ponto de vista (Jensen, 2003a). Assim, foram considerados três tipos de justificativa: de posição (o usuário da rede social apenas se posiciona de um lado da discussão, sem muitas explicações); interna (quando se utiliza de histórias pessoais para reforçar/defender seu ponto de vista); e externa (uso de outras fontes de informação para sustentar sua posição) (Jensen, 2003a; Cervi, 2013). Essa variável se torna fundamental à análise de um debate público por contribuir com "as condições de deliberação necessárias e seus resultados substantivos" (Bohman, 1998, p. 404 - tradução própria).

Por fim, é observada a reflexividade, que consiste em observar se os comentadores expressaram persuasão (i.e., estiveram concentrados em convencer outros ou mostraramse convencidos com os argumentos alheios), progresso (quando se preocuparam em inserir informações a fim de enriquecer a discussão) ou radicalização (apresentaram discurso desrespeitoso, utilizando-se de expressões ofensivas e/ou preconceituosas) (Jensen, 2003a).

Desse modo, trabalha-se com as seguintes hipóteses:

H1: Apesar de as redes sociais terem ampliado o acesso à discussão eleitoral, o debate online em comentários de publicações jornalísticas no Facebook, especialmente, afasta-se de um modelo de debate deliberativo normativo, possuindo características menos rígidas nas ocorrências de reciprocidade e progresso, pelo próprio fato de o espaço em que se desenvolve o debate não ser político em si.

H2: Mesmo que as páginas de jornais na rede Facebook não sejam, especificamente, espaços políticos, há a possibilidade de os usuários as usarem para dialogar a fim de persuadirem outros em relação a sua posição política.

\footnotetext{
7 Teste que tem por finalidade identificar em que pares há uma concentração de casos, ou seja, quais categorias das variáveis tendem a estar mais próximas ou distantes. Os valores são considerados significativos quando estão acima ou abaixo de $|+|-1,96 \mid$, respectivamente.
} 
ISABELE BATISTA MITOZO; MICHELE GOULART MASSUCHIN; FERNANDA CAVASSANA DE CARVALHO

Deve-se ressaltar que, apesar de os dados terem sido extraídos por meio de um aplicativo, a coleta foi realizada manualmente pelos pesquisadores, i.e., todos os comentários foram lidos, o que permitiu observar se faziam alguma referência a outros comentários ou se os comentadores apenas postavam sua opinião, desconsiderando os demais participantes e comentários, desse modo, não deixamos isso a cabo da tecnicidade do aplicativo. Portanto, a partir da observação do conteúdo dos comentários foi possível essa categorização de acordo com as três variáveis já citadas, além da medição da intensidade do debate, conforme segue na análise abaixo.

\section{Intensidade do debate}

Antes de iniciar a análise do conteúdo do debate, faz-se necessária uma breve apresentação da intensidade dos comentários nos perfis dos veículos em estudo durante a campanha presidencial. Para tanto, recorre-se à distribuição destes ao longo do tempo. Como já observado anteriormente neste artigo, são considerados apenas os comentários que citaram ao menos um dos três principais candidatos feitos a posts que também os mencionaram.

A Tabela 1 traz as informações de frequência de comentários por jornal e por semana, bem como os resíduos padronizados (Rp). A partir dessa tabela, pode-se afirmar que o perfil do jornal Folha de S. Paulo (FSP) concentrou 68,3\% dos comentários, no período analisado, seguido por O Estado de S. Paulo (ESP), com 18,4\%, e O Globo (OGL), que totalizou $13,3 \%$. Percebe-se, portanto, que há uma grande concentração, em termos quantitativos, em um único jornal, mesmo que as postagens se distribuam de forma equilibrada (FSP: 5.675; ESP: 5.091; OGL: 4.028). Recordando o total de comentários analisados - mais de 610 mil -, percebe-se que, de cada dez comentários analisados, pelo menos seis deles haviam sido feitos em posts da FSP. Deve-se ressaltar que, entre os três veículos nacionais, este é o que possui maior número de seguidores também.

Ao olhar para o número de comentários a cada semana, percebe-se que, em todas elas, a FSP se mantém com o perfil mais comentado em relação à campanha presidencial. Porém, na comparação direta entre ESP e $O G L$, pode ser notado que nem sempre o ESP esteve à frente do jornal carioca. Ao concentrar a análise nos resíduos padronizados, identificados na Tabela 1, é possível observar em que semanas houve alta ou baixa concentração de comentários superior ao esperado: 
Tabela 1

Comentários por semana nos jornais

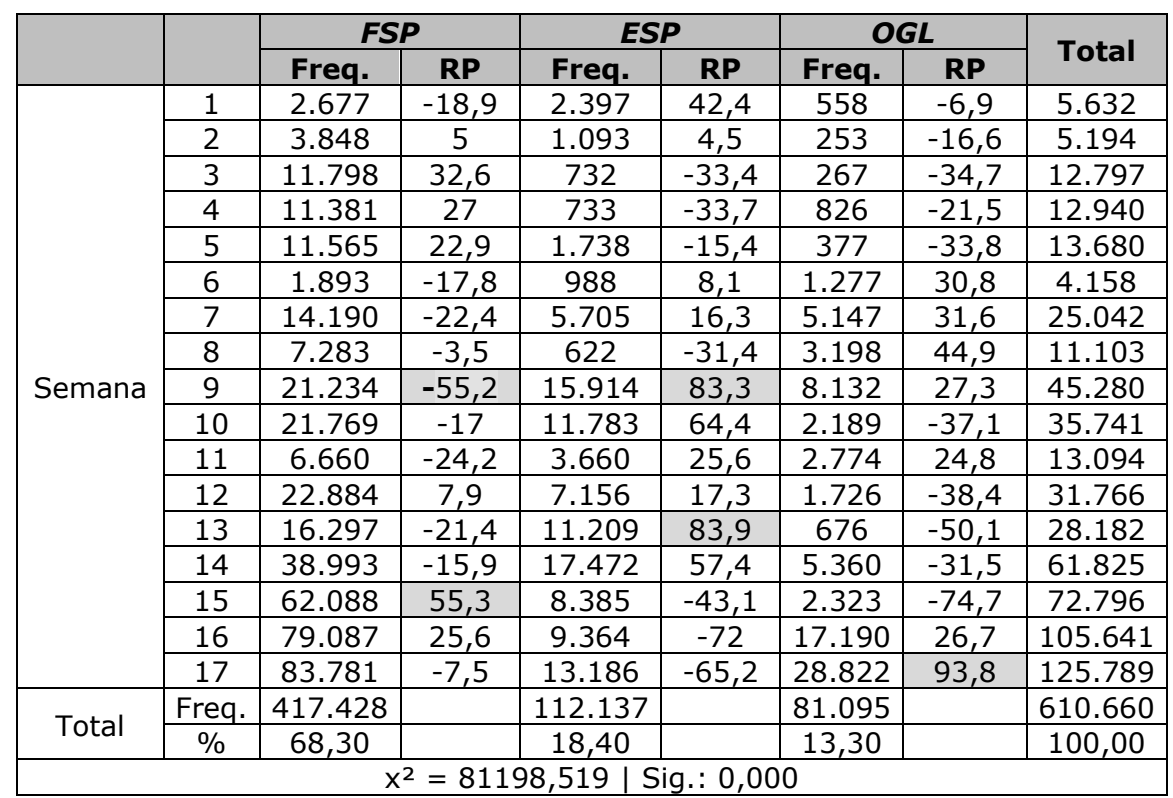

Fonte: Elaboração própria com dados do Grupo de Pesquisa em Comunicação Política e Opinião Pública - CPOP/UFPR.

Nos posts da $F S P$, a semana 15 concentrou o maior número de comentários (Rp $55,3)$, quando comparada aos outros jornais na semana e em relação aos comentários na própria FSP nas demais semanas. A semana 15 é imediatamente posterior ao primeiro turno do pleito, ou seja, trouxe os primeiros resultados da disputa e iniciou a cobertura do segundo turno. Em contrapartida, a semana 9 apresenta o maior resíduo padronizado negativo para esse jornal (Rp -55,2). Uma das causas para essa relação negativa na comparação está na elevada concentração de comentários sobre a campanha no ESP, que apresenta um alto resíduo positivo ( $\mathrm{Rp} 83,3)$ na referida semana. O maior resíduo positivo é encontrado em $O G L$, na última semana (17), em que os posts desse jornal chegaram a agregar 28.822 comentários, o que esteve muito acima do "normal" das semanas anteriores. As diferenças entre os comentários nesses três jornais, por semana, podem ser visualizadas no Gráfico 1 : 
Gráfico 1

Comentários nos posts dos jornais ao longo das semanas

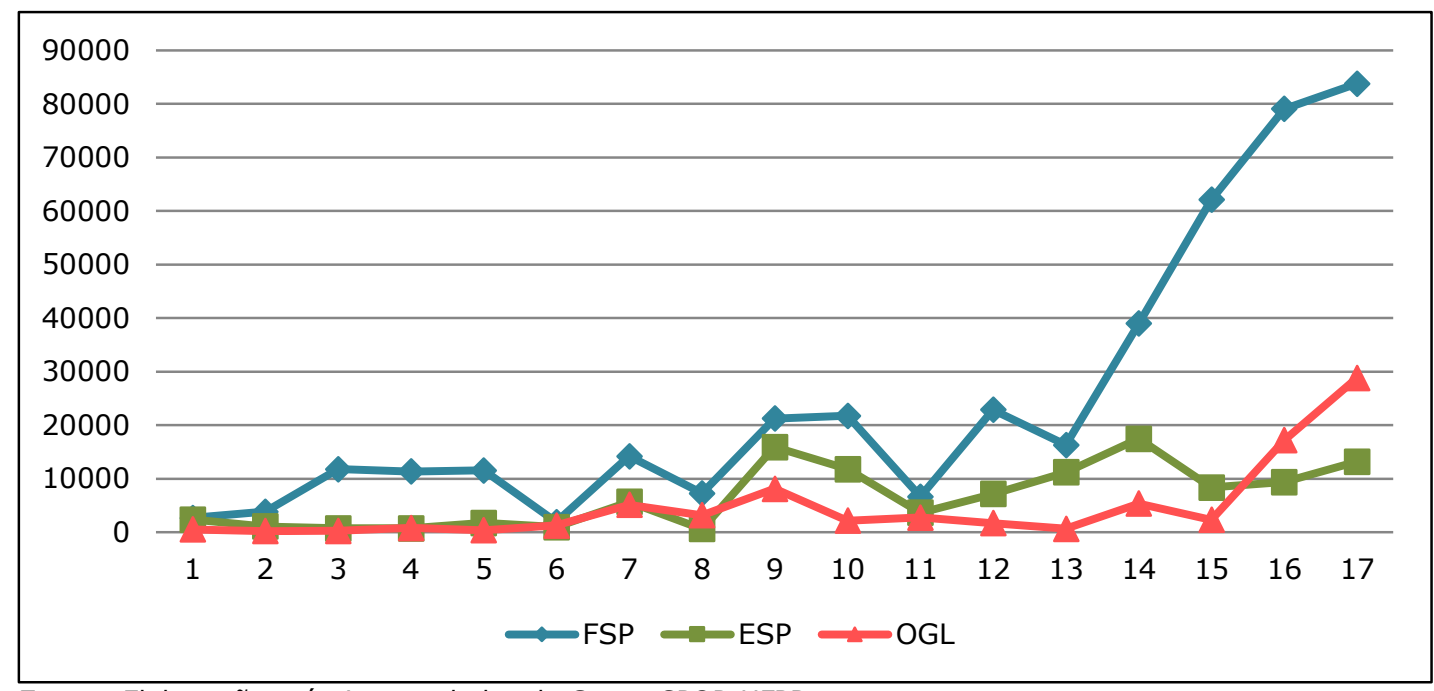

Fonte: Elaboração própria com dados do Grupo CPOP-UFPR.

Visualizando a intensidade do debate nos três jornais ao longo das semanas, é possível verificar que, comparativamente, o OGL supera, em número de comentários, o ESP em algumas semanas, como a 6 e a 8, assumindo a segunda colocação em número de comentários nas duas últimas semanas. Também é perceptível que as quedas na quantidade dos comentários seguem eventos pontuais na campanha. As semanas 6 e 8 apresentam quedas nos três jornais. Já na semana 11, há quedas na FSP e no ESP, mas ligeira alta no OGL. Essas oscilações podem ser resultado de temas mais (ou menos) polêmicos tratados nas postagens (Sampaio e Barros, 2010).

O Gráfico 1 também permite afirmar que, de maneira geral, os comentários em posts de jornais nacionais tenderam a seguir um equilíbrio durante a campanha, com quedas e picos sintomáticos, refletidos nos três jornais. Acredita-se que os eventos que pautaram o crescimento no número de comentários nas semanas de pico influenciaram a intensidade do debate no Facebook em todos os jornais sem muita discrepância entre eles. Há algumas diferenças nítidas, como na semana 13 , em que os comentários no ESP crescem de forma mais intensa do que nos demais jornais, e em $O G L$, quando o debate se intensifica subitamente no final do período eleitoral.

Até aqui, a análise se manteve, predominantemente, relacionada à frequência dos comentários por semana e às diferenças e similitudes entre eles ao longo do tempo. A partir da próxima subseção, é analisada, então, a qualidade do debate nas páginas de Facebook desses jornais a partir das três variáveis, mencionadas anteriormente: postura do comentador, justificativa e reflexividade. 
DEBATE POLÍTICO-ELEITORAL NO FACEBOOK

Postura do comentador

Em relação à postura do comentador, o Gráfico 2 permite a comparação visual dos comentários em posts dos três jornais durante o primeiro turno. A primeira informação que chama a atenção é, mais uma vez, a alta frequência de comentários na $F S P$, em comparação com o OGL e o ESP, o que já havia sido identificado anteriormente nos dados apresentados na Tabela 1 e no Gráfico 1. A informação nova que ele nos traz é que o debate é majoritariamente monológico para os três jornais; no entanto, na FSP, em termos de proporção, a diferença é maior, com quase 350 mil comentários identificados com essa postura entre os comentadores.

Esses dados retomam a discussão teórica no que diz respeito a uma participação bastante relevante em termos quantitativos quando, nos comentários, opina-se sobre temas políticos, não havendo, no entanto, um diálogo propriamente dito, como ressalta Dahlberg (2001) ao tratar dos "problemas" da interação por meio de ferramentas online. Ainda que o Facebook possa ser considerado um espaço de participação, a interação entre os participantes ainda é limitada, seja em relação ao conteúdo ou em relação aos demais usuários (Dahlgren, 2005), eles mais "falam sozinhos" do que interagem (Cervi, 2013).

Gráfico 2

Postura dos comentadores em posts dos jornais

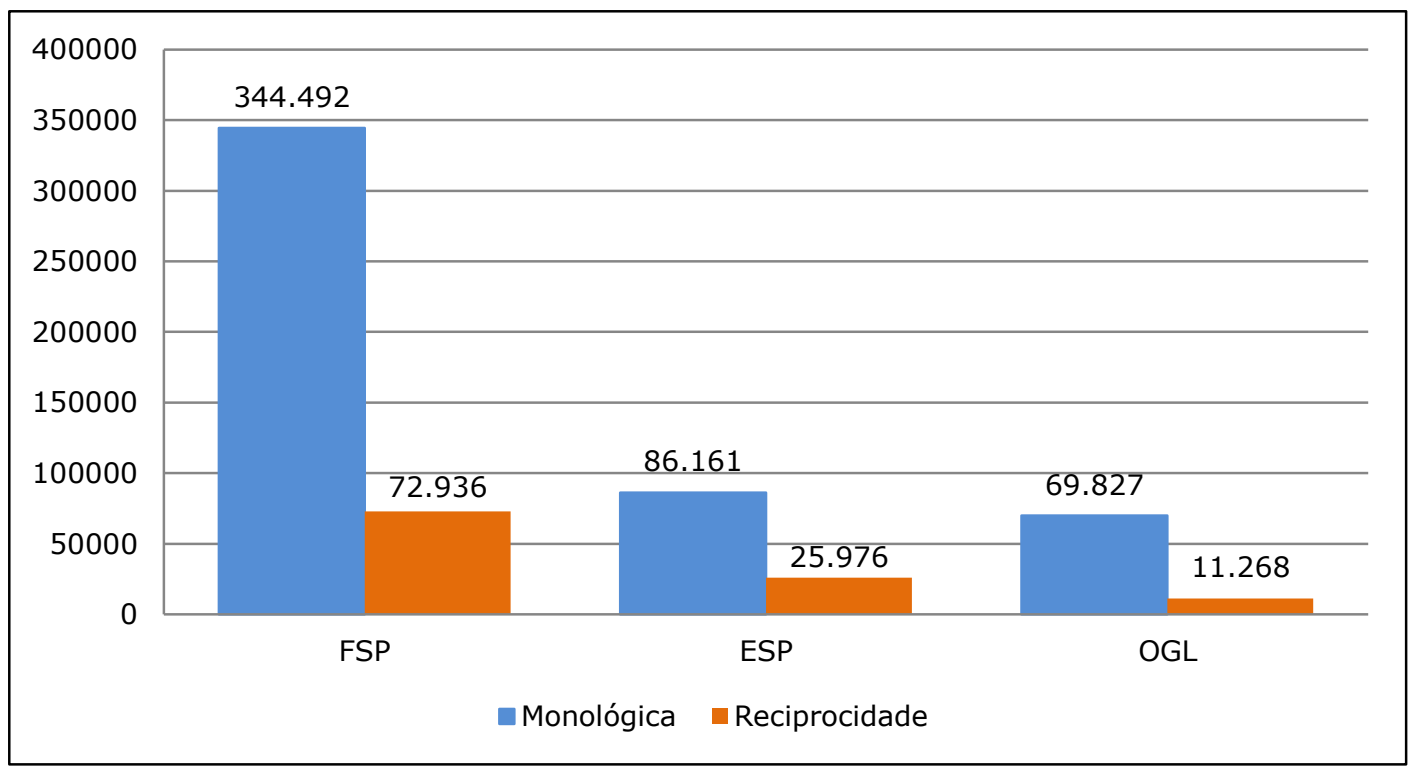

Fonte: Elaboração própria com dados do Grupo CPOP-UFPR.

Quanto aos comentários com reciprocidade, que são o oposto dos comentários monológicos, na FSP eles passam dos 70 mil, quantia quase três vezes maior que os presentes no ESP, chegando a representar sete vezes os do OGL. O Gráfico 2, no entanto, não é suficiente para que os comentários dos três jornais sejam comparados diretamente, 
ISABELE BATISTA MITOZO; MICHELE GOULART MASSUCHIN; FERNANDA CAVASSANA DE CARVALHO

entre si, a partir da postura do comentador. Isso porque só apresenta os valores absolutos, e devem ser levadas em consideração as características individuais de cada jornal, bem como o total de comentários neles em todo o período analisado. Para tanto, a Tabela 2 traz a frequência de comentários, por jornal, para as duas posturas possíveis de ser assumidas pelos comentadores, bem como os resíduos padronizados. Assim, possibilita-se a comparação direta entre as variáveis "postura do comentador" e "jornal".

Tabela 2

Postura dos comentadores nos posts dos jornais

\begin{tabular}{|c|c|c|c|c|c|c|c|c|}
\hline & & \multicolumn{2}{|c|}{ FSP } & \multicolumn{2}{|c|}{ ESP } & \multicolumn{2}{|c|}{ OGL } & \multirow{2}{*}{ Total } \\
\hline & & Freq. & $\mathbf{R P}$ & Freq. & $\mathbf{R P}$ & Freq. & $\mathbf{R P}$ & \\
\hline \multirow{2}{*}{ Postura } & Monológica & 344.492 & 4,1 & 86.161 & $-18,9$ & 69.827 & 13 & 500.480 \\
\hline & Recíproca & 72.936 & $-8,7$ & 25.976 & 40,4 & 11.268 & $-27,8$ & 110.180 \\
\hline Total & & 417.428 & & 112.137 & & 81.095 & & 610.660 \\
\hline
\end{tabular}

Fonte: Elaboração própria com dados do Grupo CPOP-UFPR.

Com todos os resíduos significativos e altos, pode-se constatar que os debates na FSP e no OGL tendem a ser mais monológicos que recíprocos. O OGL, porém, apresenta os maiores resíduos padronizados entre os três jornais, positivo para monológico (Rp 13) e negativo para reciprocidade (Rp -27,8), superando a $F S P$ (Rp 4,1 e -8,7, respectivamente). Já o ESP é o único que apresenta resíduo negativo para monológico (Rp -18,9) e resíduo alto positivo (Rp 40,4) para comentários com reciprocidade, sendo esse o maior resíduo padronizado da Tabela 2 . Ou seja, na comparação direta entre as categorias dessas variáveis, há uma concentração de comentários recíprocos no $E S P$, distanciando-o dos outros dois veículos.

Assim, o ESP tende a ser o jornal que mais apresenta debate - em termos de interação - entre os seus comentadores, no Facebook, enquanto o OGL é o jornal que agrega mais comentários monológicos, sem abertura para o diálogo. Embora o ESP agregue menos participação em termos quantitativos, se comparado à $F S P$, por exemplo, as características dos comentários postados em sua página constituem um modelo mais próximo do diálogo. Essa descoberta pode ser tomada como uma das principais deste artigo, uma vez que o ESP é, declaradamente, o mais conservador entre os três jornais analisados. Por essa visão política mais fechada do veículo, esperava-se que o público seguidor do Facebook fosse menos aberto ao diálogo.

Esse resultado pode ser explicado por duas ponderações presentes na literatura. Primeiramente, pelo fato de os seguidores em uma rede social poderem ter visões distintas, um público mais variado em relação àquele que assina o impresso ou a versão online, o que amplia a possibilidade do debate, já que o diálogo também pode se estabelecer em relações antagônicas, como assinala Dahlberg (2001). É claro que não se pode deixar de ressaltar que esta análise não se relaciona diretamente com a produção do 
DEBATE POLÍTICO-ELEITORAL NO FACEBOOK

post pelo jornal, uma vez que a unidade de análise, aqui, limita-se aos comentários sobre a campanha política.

Sob um segundo ponto de vista, de modo divergente, esse diálogo pode corresponder justamente a um processo de segmentação (Dahlgren, 2005) que ocorre no universo online quando um grupo muito fechado se reúne em um espaço e, por ter muitas afinidades e opiniões similares, consegue dialogar. É mais fácil "conversar" com quem compartilha das mesmas ideias ou pontos de vista (Sunstein, 2003). Ou seja, pode haver um público muito parecido com o perfil do jornal e, por isso, existir facilidade em manter o diálogo.

Uma possível explicação para esse achado sobre o ESP é que o comentador desse veículo já está habituado há mais tempo a comentar suas notícias, uma vez que esse foi o primeiro jornal que abriu aos leitores, assinantes ou não, a possibilidade de comentar notícias em seu portal online. Por outro lado, não se pode fazer tal afirmação sem a realização de uma pesquisa empírica, pois: 1) o comentador de Facebook pode não ser o mesmo que visita o portal: e 2) a comodidade de o leitor não precisar ir ao portal, já que o portal vem até ele (como é a página de Facebook), provavelmente atrai mais comentadores.

Vale ressaltar, ainda, que essa informação de que os comentários do ESP são mais recíprocos e menos monológicos que os demais não necessariamente garante a qualidade do diálogo nos comentários desse veículo, uma vez que, ainda que o comentador esteja disposto a ler e responder comentários de outros, pode fazê-lo com diferentes características, inclusive ofensas ou agressões verbais, o que não constitui um diálogo pautado no respeito e no progresso do debate. Por isso, faz-se necessária a análise de outras características, apresentada nas subseções seguintes.

\section{Justificativa}

Observando a presença ou não de justificativa, os primeiros dados relevantes da Tabela 3 e do Gráfico 3 indicam que há predomínio do formato "posição" em 76,8\% de todos os comentários analisados. Nesse tipo de formato, o participante não adiciona nenhum tipo de informação para dar embasamento a sua afirmação ou tomada de posição. Trata-se apenas de vaga opinião em relação a algum tema ou participante da conversação. Esse formato é contraditório ao debate deliberativo, pois, como argumenta Jensen (2003b), para assumir essa característica ele precisa apresentar informação, argumento e reciprocidade. Apenas com o posicionamento, tem-se uma ausência grande de conteúdo informativo na conversação online. O Gráfico 3 ilustra essa discrepância e mostra como esse formato de posição é recorrente nos três veículos e se sobrepõe aos demais, especialmente na FSP, com mais de 300 mil comentários com essa característica. 
ISABELE BATISTA MITOZO; MICHELE GOULART MASSUCHIN; FERNANDA CAVASSANA DE CARVALHO

Gráfico 3

Justificativa dos comentadores em posts dos jornais

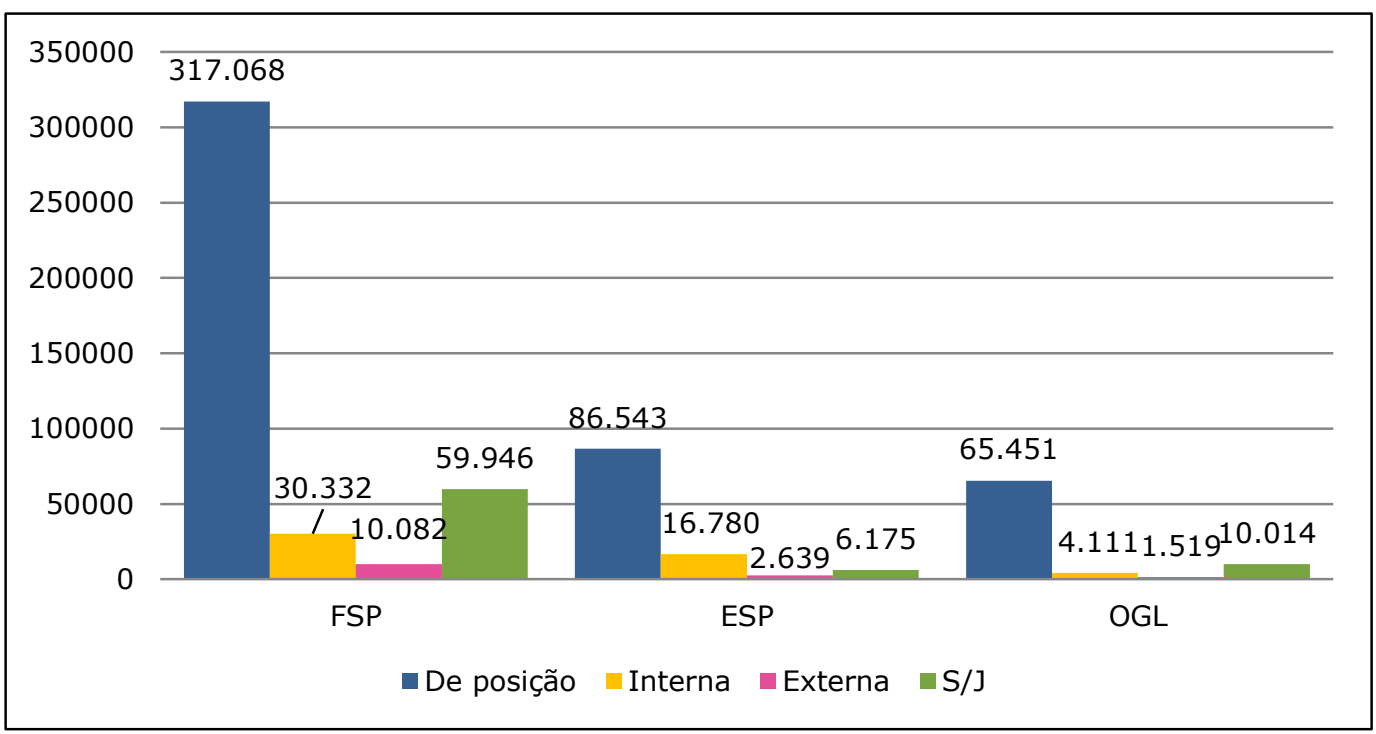

Fonte: Elaboração própria com dados do Grupo CPOP-UFPR.

A justificativa interna aparece em $8,4 \%$ dos comentários e caracteriza-se pelo uso de informações próprias, que, na maioria das vezes, consistem na expressão de experiências cotidianas. Aquela que mais adicionaria conteúdo - a externa - aparece somente em $2,3 \%$ dos textos, i.e., poucos comentários se utilizam de dados, links e informações trazidas de outros espaços. Vale destacar que a pesquisa feita por Strandberg e Berg (2013) considerou um grau de justificação satisfatório no debate de comentários de jornais, ainda que tenha havido predomínio do tipo "interna", uma vez que o cidadão leigo não precisa obrigatoriamente refinar sua justificativa para que ela seja considerada válida.

Tabela 3

Tipo de justificativa por jornal

\begin{tabular}{|c|c|c|c|c|c|c|c|c|c|c|c|}
\hline & \multicolumn{3}{|c|}{ FSP } & \multicolumn{3}{|c|}{ ESP } & \multicolumn{3}{|c|}{ OGL } & \multicolumn{2}{|c|}{ Total } \\
\hline & Freq. & $\%$ & RP & Freq. & Porc. & $\mathbf{R P}$ & Freq. & Porc. & RP & Freq. & Porc. \\
\hline De posição & $\begin{array}{c}317.06 \\
8\end{array}$ & 76,0 & $-6,3$ & 86.543 & $\begin{array}{c}77,2 \\
0\end{array}$ & 1,4 & 65.451 & $\begin{array}{c}80,7 \\
0 \\
\end{array}$ & 12,7 & $\begin{array}{c}469.06 \\
2\end{array}$ & $\begin{array}{c}76,8 \\
0\end{array}$ \\
\hline Interna & 30.332 & 7,3 & -25 & 16.780 & $\begin{array}{c}15,0 \\
0\end{array}$ & 76 & 4.111 & 5,10 & $-32,6$ & 51.223 & 8,40 \\
\hline Externa & 10.082 & 2,4 & 3,5 & 2.639 & 2,40 & 0,5 & 1.519 & 1,90 & $-8,6$ & 14.240 & 2,30 \\
\hline$S / J$ & 59.946 & 14,4 & $\begin{array}{c}34 \\
6\end{array}$ & 6.175 & 5,50 & -66 & 10.014 & & -1 & 76.135 & $\begin{array}{c}12,5 \\
0\end{array}$ \\
\hline Total & $\begin{array}{c}417.42 \\
8 \\
\end{array}$ & 100 & & $\begin{array}{c}112.13 \\
7 \\
\end{array}$ & 100 & & 81.095 & 100 & & $\begin{array}{c}610.66 \\
0 \\
\end{array}$ & 100 \\
\hline
\end{tabular}

Fonte: Elaboração própria com dados do Grupo CPOP-UFPR. 
DEBATE POLÍTICO-ELEITORAL NO FACEBOOK

As categorias da variável justificativa, embora se distribuam de maneira parecida de acordo com os percentuais, apresentam tendências quando se aplica o teste dos resíduos padronizados para poder fazer comparações entre os veículos e ver quais concentram determinado tipo de justificação em relação aos outros. De forma mais marcante, a partir da Tabela 3, pode-se perceber que no ESP o comentador se mostrou mais propício a apresentar narrativas pessoais para justificar sua posição ( $R p=76,0)$, tendo sido esse o único veículo a apresentar Rp positivo e alto nessa categoria.

Apesar da concentração de comentários que apenas apresentavam posição, comparativamente e de modo proporcional, o ESP tende a apresentar mais comentários com justificação, ainda que interna. Destaca-se que esse jornal já apresentava mais comentários com reciprocidade - conforme dados anteriores - e agora é o que apresenta maior nível de justificação. Por outro lado, e também seguindo resultados anteriores quem mais deixa a desejar em termos de justificação ( $R p 12,7)$ é o comentador de $O G L$, jornal que antes já havia concentrado mais monólogos. De modo comparativo, o OGL é o veículo com maior percentual na categoria posição, chegando a $80,7 \%$. Nesse critério de análise do debate nos comentários, tem-se também um resultado que indica um uso muito restrito de informação adicionada aos comentários.

\section{Reflexividade}

Em relação à terceira característica que o texto propõe analisar, a reflexividade, há uma concentração de comentários enquadrados na categoria persuasão $(24,8 \%)$. A categoria que menos se identificou foi "progresso" $(5,2 \%)$ e que seria aquela que mais se aproxima da ideia de um debate duradouro, considerando os demais comentadores. No trabalho de Massuchin e Campos (2015), em que as autoras analisam o debate em websites de campanha dos candidatos, um espaço mais homogêneo, há maior evidência de progresso, que alcança até $30 \%$ dos comentários analisados. O Gráfico 4 indica a alta incidência de persuasão nos comentários analisados, que assim se sobressai ante os demais formatos, principalmente em relação ao progresso: 
ISABELE BATISTA MITOZO; MICHELE GOULART MASSUCHIN; FERNANDA CAVASSANA DE CARVALHO

\section{Gráfico 4}

Reflexividade dos comentadores em posts dos jornais

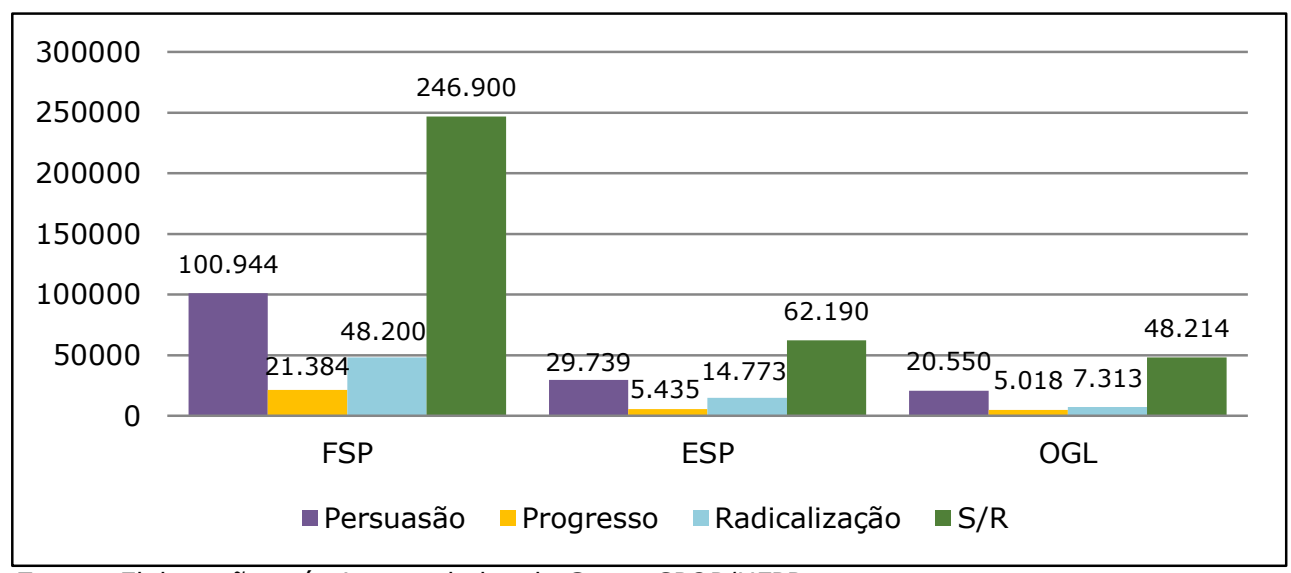

Fonte: Elaboração própria com dados do Grupo CPOP/UFPR.

Por outro lado, chamam a atenção os $11,5 \%$ de comentários que radicalizam o debate. Esse dado mostra que um em cada dez comentários apresenta essa característica, usando termos inadequados e ofensivos, descaracterizando o debate respeitoso. Isso pode ocorrer, segundo Amossy (2011), por se tratar de um espaço mais heterogêneo - diferente de sites de partidos, por exemplo -, que apresenta uma temática mais conflitiva, como a política eleitoral. Os dados indicados por Amossy (2011) mostram que esse resultado não é específico dos jornais brasileiros, pois a autora encontrou o que caracteriza como flames em jornais franceses analisados. Segundo ela, isso acontece porque um tema polêmico é confrontado e deixa de ser polêmico para transformar-se em flames, com violência verbalizada.

Tabela 4

Tipo de reflexividade por jornal

\begin{tabular}{|c|c|c|c|c|c|c|c|c|c|c|c|}
\hline & \multicolumn{3}{|c|}{ FSP } & \multicolumn{3}{|c|}{ ESP } & \multicolumn{3}{|c|}{ OGL } & \multirow{2}{*}{\multicolumn{2}{|c|}{ Total }} \\
\hline & Freq. & $\%$ & $\mathbf{R P}$ & Freq. & $\%$ & RP & Freq. & $\%$ & $\mathbf{R P}$ & & \\
\hline Persuasão & 100.944 & 24,20 & $-7,6$ & 29.739 & 26,50 & 11,8 & 20.550 & 25,30 & 3,3 & 151.233 & 24,80 \\
\hline Progresso & 21.384 & 5,10 & $-2,6$ & 5.435 & 4,80 & $-5,4$ & 5.018 & 6,20 & 12,2 & 31.837 & 5,20 \\
\hline Radicalização & 48.200 & 11,50 & 0,7 & 14.773 & 13,20 & 16,4 & 7.313 & 9,00 & $-20,9$ & 70.286 & 11,50 \\
\hline$S / R$ & 246.900 & 59,10 & 5,4 & 62.190 & 55,50 & $-13,4$ & 48.214 & 59,50 & 3,5 & 357.304 & 58,50 \\
\hline Total & 417.428 & 100 & & 112.137 & 100 & & 81.095 & 100 & & 610.660 & 100 \\
\hline
\end{tabular}

Fonte: Elaboração própria com dados do Grupo CPOP-UFPR.

Apesar dessa predominância da persuasão e do uso dos comentários para o convencimento dos demais participantes do debate, de modo comparativo algumas características sobressaem em alguns veículos. Embora os percentuais sejam semelhantes, os resíduos padronizados mostram que há diferenças. A persuasão, característica predominante, se destaca no $E S P$, o qual apresenta resíduo positivo alto $(\operatorname{Rp} 11,8)$ em relação à $F S P$, que é o único veículo a apresentar um $\operatorname{Rp}$ negativo $(-7,6)$, e também em 
DEBATE POLÍTICO-ELEITORAL NO FACEBOOK

relação ao $O G L$, com um resíduo mais baixo ( $R p 3,3)$. Progresso, a categoria que menos aparece nos comentários, concentra-se no $O G L(R p 12,2)$, que até então era o veículo com menor chance de reciprocidade e justificação.

Em relação à radicalização, apesar de, em valores absolutos, ela aparecer em muitos comentários da FSP, proporcionalmente concentra-se no ESP (Rp 16,4) e apresenta-se de maneira mais escassa em OGL (Rp -20,9). Tendo em vista que o comentador do ESP, conforme visto na seção anterior, é aquele mais recíproco no debate, confirma-se o que já havia sido destacado: a presença de reciprocidade não significa que o debate progrediu. No caso desse jornal, aqueles que comentaram usaram a reciprocidade para atacar o posicionamento de outros.

\section{Características de modo relacionado}

A fim de realizar uma análise mais ampla da qualidade do debate desenvolvido nas páginas de Facebook dos jornais apresentados, decidiu-se realizar um cruzamento das variáveis entre si, não mais considerando as características dos comentadores por jornal, mas as do total de comentários analisados. O objetivo é saber como essas características aparecem associadas, e, desse modo, apresenta-se, primeiramente, a relação entre a postura do comentador e o tipo de justificativa expressado.

Tabela 5

Postura do comentador $\mathbf{x}$ Tipo de justificativa nos comentários

\begin{tabular}{|l|c|c|c|c|}
\hline & & Monológica & Recíproca & Total \\
\hline \multirow{3}{*}{ De posição } & Freq. & 38.4371 & 84.691 & 469.062 \\
\cline { 2 - 5 } & $\%$ & 81,90 & 18,10 & 100,00 \\
\cline { 2 - 5 } & RP & $-0,10$ & 0,20 & \\
\hline \multirow{3}{*}{ Interna } & Freq. & 33.626 & 17.597 & 51.223 \\
\cline { 2 - 5 } & $\%$ & 65,60 & 34,40 & 100,00 \\
\cline { 2 - 5 } & RP & $-40,80$ & 86,90 & \\
\hline \multirow{3}{*}{ Externa } & Freq. & 11.381 & 2.859 & 14.240 \\
\cline { 2 - 5 } & $\%$ & 79,90 & 20,10 & 100,00 \\
\cline { 2 - 5 } & RP & $-2,70$ & 5,70 & \\
\hline \multirow{3}{*}{ Total } & Freq. & 71.102 & 5.033 & 76.135 \\
\cline { 2 - 5 } & $\%$ & 93,40 & 6,60 & 100,00 \\
\cline { 2 - 5 } & RP & 34,80 & $-74,30$ & \\
\hline & Freq. & 500.480 & 110.180 & 610.660 \\
\cline { 2 - 5 } & $\%$ & 82,00 & 18,00 & 100,00 \\
\hline
\end{tabular}

Fonte: Elaboração própria com dados do Grupo CPOP-UFPR.

Percebe-se pela Tabela 5 que o comentador recíproco tende fortemente a apresentar justificativa interna, o que se pode constatar pelo Rp alto positivo $(86,9)$. Assim, pode-se dizer que esse tipo de comentador divide com outro(s) experiências pessoais que explicam sua argumentação. Também há um Rp positivo, embora não muito alto, de 5,7, relacionando os comentários que apresentam reciprocidade com a justificativa externa. Os comentários que apenas ressaltam posição se distribuem de forma muito semelhante entre 
ISABELE BATISTA MITOZO; MICHELE GOULART MASSUCHIN; FERNANDA CAVASSANA DE CARVALHO

comentários recíprocos e monológicos, o que indica que eles independem da predisposição do comentador. Por outro lado, quando os comentários são monológicos, há uma tendência a serem desprovidos de justificação $(\mathrm{S} / \mathrm{J})$, algo que ocorre de forma contrária quando são recíprocos, utilizando-se a justificação, portanto, quando há diálogo, seja para convencer ou dar progressão à conversa.

Observando a relação entre postura do comentador e reflexividade expressa (Tabela 6), pode-se afirmar que, ainda que os comentários sejam majoritariamente monológicos, como já foi identificado, nos comentários recíprocos a tendência é de que haja mais progresso (Rp 153,8). A tentativa de persuadir também aparece mais em comentários recíprocos ( $\mathrm{Rp} 18,9$ ), no entanto, isso era algo esperado, já que essa característica normalmente é direcionada a alguém e, por isso, o comentário é recíproco. Outro dado que confirma o desinteresse pelo debate por parte dos comentadores monológicos é o fato de que eles se aproximam da categoria S/R - sem reflexividade (Rp 49,0).

Tabela 6

Postura do comentador $\mathbf{x}$ Reflexividade nos comentários

\begin{tabular}{|c|c|c|c|c|}
\hline & & Monológica & Recíproca & Total \\
\hline \multirow{3}{*}{ Persuasão } & Freq. & 120.822 & 30.411 & 151.233 \\
\hline & $\%$ & 79,90 & 20,10 & 100,00 \\
\hline & RP & $-8,90$ & 18,90 & \\
\hline \multirow{3}{*}{ Progresso } & Freq. & 14.434 & 17.403 & 31.837 \\
\hline & $\%$ & 45,30 & 54,70 & 100,00 \\
\hline & RP & $-72,20$ & 153,80 & \\
\hline \multirow{3}{*}{ Radicalização } & Freq. & 45.874 & 24.412 & 70.286 \\
\hline & $\%$ & 65,30 & 34,70 & 100,00 \\
\hline & RP & $-48,90$ & 104,20 & \\
\hline \multirow{3}{*}{$S / R$} & Freq. & 319.350 & 37.954 & 357.304 \\
\hline & $\%$ & 89,40 & 10,60 & 100,00 \\
\hline & RP & 49,00 & $-104,40$ & \\
\hline \multirow{2}{*}{ Total } & Freq. & 500.480 & 110.180 & 610.660 \\
\hline & $\%$ & 82,00 & 18,00 & 100,00 \\
\hline \multicolumn{5}{|c|}{$X^{2}=55852,896 \mid$ Sig 0,000} \\
\hline
\end{tabular}

Fonte: Elaboração própria com dados do Grupo CPOP-UFPR.

Um dado curioso da Tabela 6 é que a radicalização é uma característica que não fica muito distante na distribuição das ocorrências de reciprocidade (Rp 104,2). Isso indica que nem sempre ser recíproco significa aumentar a qualidade do debate e progredir ou persuadir. Há casos em que a referência aos demais participantes é carregada de ofensas ao candidato, ao repórter ou ao outro comentador, como ressalta Amossy (2011). Por isso, como se observa na Tabela 6, a radicalização esteve mais relacionada aos comentários recíprocos que aos monológicos ( $R p-48,9$ ). Ainda que a reciprocidade seja importante ao debate (Jensen, 2003a), sozinha ela não diz muita coisa, pois não garante um debate baseado no respeito ou na civilidade (Papacharissi, 2004). Da mesma forma que ela oferece espaço para o crescimento do debate qualificado, dá oportunidade para a radicalização das relações entre os comentadores, resultado da polarização eleitoral e do conservadorismo político que se reflete na ágora digital (Chaia e Brugnago, 2015). 
DEBATE POLÍTICO-ELEITORAL NO FACEBOOK

Além da relação de postura com reflexividade e justificativa, observa-se como essas duas últimas tendem a aparecer quando relacionadas. Nesta parte da análise, podese constatar que progresso é uma característica fortemente aliada à existência de justificativa, tanto interna ( $R p$ 115,8) quanto externa ( $R p 111,4)$. Isso significa dizer que os comentadores, em sua maioria, só conseguem progredir no diálogo quando agregam informação a algum tipo de justificativa.

Tabela 7

Justificativa do comentador $x$ Reflexividade

\begin{tabular}{|c|c|c|c|c|c|c|}
\hline & & Persuasão & Progresso & Radicalização & S/R & Total \\
\hline \multirow{3}{*}{ De posição } & Freq. & 129.910 & 18.544 & 61.321 & 259.287 & 469.062 \\
\hline & $\%$ & 85,90 & 58,20 & 87,20 & 72,60 & 76,80 \\
\hline & RP & 40,30 & $-37,80$ & 31,60 & $-29,00$ & \\
\hline \multirow{3}{*}{ Interna } & Freq. & 14.330 & 8.655 & 7.777 & 20.461 & 51.223 \\
\hline & $\%$ & 9,50 & 27,20 & 11,10 & 5,70 & 8,40 \\
\hline & $\mathrm{RP}$ & 14,60 & 115,80 & 24,50 & $-54,90$ & \\
\hline \multirow{3}{*}{ Externa } & Freq. & 5.577 & 3.778 & 641 & 4.244 & $14 . .240$ \\
\hline & $\%$ & 3,70 & 11,90 & 0,90 & 1,20 & 2,30 \\
\hline & $\mathrm{RP}$ & 34,50 & 111,40 & $-24,70$ & $-44,80$ & \\
\hline \multirow{3}{*}{$\mathrm{S} / \mathrm{J}$} & Freq. & 1.416 & 860 & 547 & 73.312 & 76.135 \\
\hline & $\%$ & 0,90 & 2,70 & 0,80 & 20,50 & 12,50 \\
\hline & $\mathrm{RP}$ & $-127,00$ & $-49,40$ & $-87,80$ & 136,30 & \\
\hline \multirow{2}{*}{ Total } & Freq. & 151.233 & 31.837 & 70.286 & 357.304 & 610.660 \\
\hline & $\%$ & 100,00 & 100,00 & 100,00 & 100,00 & 100,00 \\
\hline \multicolumn{7}{|c|}{33190,203 | Sig.: 0,000 } \\
\hline
\end{tabular}

Fonte: Elaboração própria com dados do Grupo CPOP-UFPR.

Por outro lado, a radicalização está ligada às justificativas fracas (quase inexistentes) de posição (Rp 31,6). É perceptível que radicalização não se relaciona com acréscimo de informações para justificar uma posição externa (Rp -24,7), o que se pôde ver mesmo pelo teor das mensagens assim classificadas (geralmente, apresentando palavras de baixo calão).

Um dado surpreendente é o fato de os comentadores terem utilizado mais relatos pessoais, i.e., justificativas baseadas em acontecimentos próximos a eles e experiências de vida, para progredir no debate (Rp 115,8), e menos persuasão em relação aos outros participantes da conversação online, já que o resíduo, apesar de positivo, é menor (Rp $14,6)$. As tentativas de persuasão se dão mais via marcação de posicionamento, em que há o resíduo mais alto ( $\mathrm{Rp} 40,3)$.

Esses últimos dados relacionando as três variáveis sobre a qualidade do debate justificação, postura e reflexividade - indicam que algumas apresentam aproximações. Vale destacar a relação entre os posts categorizados pela reciprocidade e o aumento de informação adicionada pelos participantes, revelando interesse no debate. Além disso, os três tipos de reflexividade, mesmo a radicalização, são mais evidentes quando há reciprocidade, enquanto os comentários monológicos se relacionam à ausência de categorias válidas, e, em sua maioria, representam apenas uma demarcação de posição política desagregada de qualquer outra categoria. Por fim, a progressão do diálogo tende 
ISABELE BATISTA MITOZO; MICHELE GOULART MASSUCHIN; FERNANDA CAVASSANA DE CARVALHO

a carregar mais informação (justificação interna e externa), ao contrário da radicalização e da persuasão.

\section{Considerações finais}

A migração dos veículos jornalísticos para as redes sociais online configura um novo tipo de comunicação entre eles e seus leitores, pois, através dessas redes, pode-se desenvolver o que Jensen (2003a) e Dahlberg (2001) chamam de uma extensão do debate público que ocorria, até então, apenas em espaços tradicionais. Isso porque elas permitem comentar qualquer informação postada (no estilo de um fórum, mas com uma dinamicidade maior), há circularidade dos posts e comentários, em função das características do Facebook e, principalmente, pela possibilidade de seguir as páginas, receber as informações na timeline e distribuir o conteúdo por meio dos compartilhamentos.

O estudo apresentado neste artigo teve por objetivo analisar o desenvolvimento do debate em torno da campanha presidencial, observando comentários a páginas de jornais brasileiros no Facebook, o que enfatiza o uso da ferramenta também com fins políticos. Ao realizar um panorama da discussão, observando a intensidade do debate durante todo o período eleitoral, constata-se que, na última semana do primeiro turno e em todo o segundo turno, o debate político-eleitoral entre os comentadores do Facebook torna-se muito mais intenso, característica de interesse pelo tema já identificado anteriormente em análises sobre a audiência do Horário Gratuito de Propaganda Política, em que se constata maior interesse pelo público no início, mas também no final da campanha, quando o eleitor precisa decidir o voto e a disputa se torna mais acirrada (Cervi e Massuchin, 2011). A FSP possui os posts mais atrativos aos comentadores, uma vez que ela agrega $68,3 \%$ do total de comentários, mesmo que as postagens tenham se distribuído de forma equilibrada entre as páginas dos três jornais. No entanto, as oscilações do número de comentários entre eles seguem um padrão, apresentando quedas e picos sintomáticos, refletidos em todos eles, estando o ESP à frente de OGL em quase todas as semanas, em relação ao volume de comentários.

Ao observar a postura dos comentadores, seguindo as definições de Dahlberg (2001), percebe-se que nas três páginas há predomínio de comentários monológicos, reafirmando a ideia de Cervi (2013) sobre a opção por "falar sozinho" de quem acessa e posta suas opiniões na rede. Esse resultado também chama a atenção para as diferenças quanto aos conceitos de participação e de debate, que seria algo mais exigente em termos de "qualidade" do conteúdo e da relação entre comentadores que compartilham do mesmo espaço. Isso confirma a primeira hipótese, no que diz respeito à reciprocidade: houve um distanciamento visível do que era esperado para um debate mais qualitativo, conforme os estudos apontados anteriormente.

A pesquisa constatou que o ESP teve destaque em relação aos outros jornais nacionais, FSP e $O G L$, pelo maior nível de reciprocidade de seus comentadores. Não se 
DEBATE POLÍTICO-ELEITORAL NO FACEBOOK

pode, todavia, reduzir a qualidade do debate ao simples fato de o comentador ser recíproco, como se pode ver a partir das ocorrências das outras variáveis em análise.

Quanto à justificativa apresentada nos comentários, percebe-se que posição é o formato que predomina, tendo sido identificado em $76,8 \%$ de todos os comentários analisados. De modo desagregado, percebe-se que no ESP o comentador se mostrou mais propício a apresentar narrativas pessoais para justificar sua posição, i.e., usou a justificativa interna, enquanto o OGL foi aquele com maior percentual de comentários na categoria posição, chegando a 80,7\%.

Em relação à terceira característica em análise, pode-se constatar a predominância de persuasão, como categoria válida, nos comentários. Isso confirma a segunda hipótese, a qual aponta que páginas de jornais no Facebook podem ser consideradas como espaço de persuasão política. O progresso, por sua vez, foi o que menos se expressou entre os comentadores, uma vez que pode exigir um nível mais elevado de conhecimento e propensão ao debate político. Essa última característica se concentra em $O G L$, embora este seja o jornal que agregou mais comentadores monológicos. Por outro lado, o ESP tendeu a concentrar as ocorrências de radicalização, o que mostra que os leitores recíprocos desse jornal não expressaram um debate de boa qualidade, pelo contrário, eles estiveram voltados à troca de mensagens desrespeitosas.

Observando a relação entre as categorias das variáveis, percebe-se que a justificativa de posição independe da predisposição do comentador (monológico ou recíproco), ao passo que as outras categorias mantêm relações mais estreitas: o comentador recíproco tende fortemente a apresentar justificativa interna, enquanto aqueles monológicos tendem a não apresentar justificação. Quando se cruzam as variáveis postura e reflexividade, constata-se que, quando há reciprocidade, tende a haver mais progresso.

A tentativa de persuadir também aparece mais em comentários recíprocos, enquanto comentários monológicos são aqueles que apresentam maior ausência de reflexividade. Um resultado curioso foi constatar a proximidade entre reciprocidade e radicalização, i.e., os comentadores recíprocos afrontaram outros diretamente em suas postagens. Constatou-se, ainda, que o progresso é uma característica fortemente aliada à existência de uma justificativa, tanto interna quanto externa, enquanto a radicalização se aproximou da característica posição, i.e., da quase ausência de conteúdo justificando os comentários.

Por fim, vale ressaltar que a análise apresentada neste artigo, embora não trate de todas as variáveis analisáveis nesse tipo de debate, abre importante discussão para a área, primeiramente, porque traz como objeto a produção de comentários por cidadãos em ambiente digital, enfoque que não possuem muitos trabalhos já realizados, e, segundo, porque esse debate ocorre em um espaço que, naturalmente, seria utilizado para fins lúdicos, de conversação cotidiana, o Facebook, mas que parece também ser usado para tratar de temas de interesse público, tais como "eleições", contribuindo com o aumento da participação e do interesse pelo debate político. 
Isabele Batista Mitozo - Universidade Federal do Paraná (UFPR), doutoranda em Ciência Política. E-mail: <ibmitozo@gmail.com>.

Michele Goulart Massuchin - Universidade Federal do Maranhão (UFMA), professora doutora do curso de Jornalismo. E-mail: <mimassuchin@gmail.com>.

Fernanda Cavassana de Carvalho - Universidade Federal do Paraná (UFPR), doutoranda em Ciência Política. E-mail: <cavassanaf@gmail.com>.

\section{Referências bibliográficas}

AGGIO, C.; REIS, L. Campanha eleitoral no Facebook: usos, configurações e o papel atribuído por três candidatos eleitos nas eleições municipais de 2012. In: ALDÉ, A.; MARQUES, F. P. J. (orgs.). Internet e poder local. Salvador: Edufba, 2015.

Amossy, R. "O intercâmbio polémico em fóruns de discussão online: o exemplo dos debates sobre as opções de acçoes e bónus no jornal Libération". Comunicação e Sociedade, vol. 19, p. 319-335, 2011.

BARROS, S.; CARREIRO, R. "A discussão pública e as redes sociais online: o comentário de notícias no Facebook". Revista Fronteiras - Estudos Midiáticos, São Leopoldo, vol. 17, no 2, p. 174-185, 2015.

BoHman, J. "The coming of age of deliberative democracy". The Journal of Political Philosophy, vol. 6, $n^{\circ} 4$, p. 400-425, 1998.

BRASIL. Presidência da República. Pesquisa brasileira de mídia 2015: hábitos de consumo de mídia pela população brasileira [online]. Brasília: Secom, 2014. Disponível em:

<http://www.secom.gov.br/atuacao/pesquisa/lista-de-pesquisas-quantitativas-e-qualitativas-decontratos-atuais/pesquisa-brasileira-de-midia-pbm-2015.pdf/view>. Acesso em: 6 jun. 2015.

CHAIA, V.; BRUGNAGO, F. "A nova polarização política nas eleições de 2014: radicalização ideológica da direita no mundo contemporâneo do Facebook". Aurora: Revista de Arte, Mídia e Política, São Paulo, vol. 7, no 21, p. 99-129, 2015.

CERVI, E. "Como os webleitores do 'Portal Estadão' comentaram a eleição de Dilma Rousseff em 2010: uma discussão sobre os participantes do debate público em campanhas eleitorais nos novos meios de comunicação". Explanans, Zinacantepec, México, vol. 2, no 1, p. 75-99, 2013.

CERVI, E.; MASSUCHIN, M. G. "HGPE e a formação da opinião pública no Brasil: análise das estratégias dos principais candidatos à presidência da República em 2010". In: Anais do Congresso LatinoAmericano de Opinião Pública - WAPOR, Belo Horizonte, 2011 [Online]. Disponível em: <http://www.waporbh.ufmg.br/papers/Emerson_Urizzi_Cervi_2.pdf>. Acesso em: 6 jun. 2015.

DAHLBERG, L. "The internet and democratic discourse: exploring the prospects of online deliberative forums extending the public sphere". Information, Communication and Society, vol. 4, no 4, p. 615633, 2001.

2004.

"Net-public sphere research: beyond the 'first phase'". The Public, vol. 11, p. 27-44,

DAHLGREN, P. "Internet, public spheres and political communication: dispersion and deliberation". Political Communication, vol. 22, no 2, p. 147-162, 2005.

Habermas, J. Mudança estrutural da esfera pública. São Paulo: Tempo Brasileiro, 2003. 


\section{DEBATE POLÍTICO-ELEITORAL NO FACEBOOK}

JANSSEN, D.; KIES, R. "Online forums and deliberative democracy: hypotheses, variables and methodologies". In: Conference on Empirical Approaches to Deliberative Politics [Online]. Florence, 2004. Disponível em: <http://steunpuntbov.be/rapport/s0506006_onlineforums.pdf>.

Acesso em: 21 mar. 2015.

JENSEN, J. L. "Public spheres on the internet: anarchic or government-sponsored - a comparison". Scandinavian Political Studies, vol. 26, no 4, $2003 a$.

. "Virtual democratic dialogue? Bringing together citizens and politicians". Information Polity, no 8 , p. 29-47, 2003 b.

"Online deliberation and beyond? A time-based and comparative study of Danish political debates online". MedieKultur, no 56, p. 23-43, 2014.

Massuchin, M. G.; CAmpos, E. "Debate público y webs de candidatos: la participación de los electores a través de los comentarios durante la campaña de 2014 en Brasil". In: Anais de IV Congresso da Associação Latino-Americana de Investigadores sobre Campanhas Eleitorais - Alice, 2015, Belo Horizonte [Online]. Disponível em:<http://www.alice-comunicacionpolitica.com/abrirponencia.php?f=ee0434f7c517318d9fd1288f488ea780.pdf>. Acesso em: 27 mar. 2016.

McCombs, M. A teoria da agenda: a mídia e a opinião pública. Petrópolis: Vozes, 2009.

Miguel, L. F. "As duas lógicas da ação comunicativa: democracia e deliberação no debate contemporâneo". Revista Teoria e Sociedade, no 10, p. 104-143, 2002.

NORRIS, P. Digital divide, civic engagement, information poverty, and the internet worldwide. Cambridge: Cambridge University Press, 2001.

PAPACHARISSI, Z. "Democracy online: civility, politeness, and the democratic potential of online political discussion groups". New Media \& Society, vol. 6, no 2, p. 259-283, 2004.

Penteado, C.; Avanzi, C. "Redes sociais e participação política: estudo do debate sobre o novo Código Florestal no Facebook". In: Anais do V Congresso da Associação Nacional de Pesquisadores em Comunicação Política, Curitiba, 2013.

ReCUeRo, R. Redes sociais na internet. Porto Alegre: Sulina, 2009.

SAMPAIO, R. C.; BARRos, S. A. R. "Deliberação no jornalismo online: um estudo dos comentários do Folha.com". Intexto, Porto Alegre, vol. 2, no 23, p. 183-202, jul.-dez. 2010.

SAmpaio, R. C.; MAiA, R. C.; MARques, F. P. J. A. "Participação e deliberação na internet: um estudo de caso do Orçamento Participativo Digital de Belo Horizonte". Opinião Pública, Campinas, vol. 16, no 2, p. 446-477, nov. 2010.

SANDERS, L. "Against deliberation". Political Theory, vol. 25, no 3, p. 347-364, 1997.

Sunstein, C. República.com: internet, democracia y libertad. Barcelona: Paidós, 2003.

StRANDBERG, K.; Berg, J. "Online newspapers readers comments - Democratic conversation platforms or virtual soapboxes". Comunicação e Sociedade, Braga, vol. 23, p. 110-131, 2013.

WASKO, M. Y.; FARAJ, S. "Why should I share? Examining social capital and knowledge contribution in electronic networks of practice". MIS Quarterly, vol. 29, no 1, p. 35-57, 2005.

ZAGO, G. "Circulação jornalística potencializada: o Twitter como espaço para filtro e comentário de notícias por interagentes". Comunicação e Sociedade, Braga, vol. 34, no 1, p. 249-271, 2012. 
ISABELE BATISTA MITOZO; MICHELE GOULART MASSUCHIN; FERNANDA CAVASSANA DE CARVALHO

ZAGO, G.; BASTOS, M. "Visibilidade de notícias no Twitter e no Facebook: análise comparativa das notícias mais repercutidas na Europa e nas Américas". Brazilian Journalism Research, vol. 9, n० 1, p. 116-133, 2013.

\section{Resumo}

Debate político-eleitoral no Facebook: os comentários do público em posts jornalísticos na eleição presidencial de 2014

Experiências interativas online têm estimulado o desenvolvimento de debate público. O Facebook (FB), por exemplo, atrai tanto indivíduos quanto instituições, tais como empresas jornalísticas, que veem na ferramenta a oportunidade de maior contato com a audiência. Com base nisso, este artigo investiga as características do debate público acerca da eleição presidencial de 2014, a partir de postagens nas páginas oficiais dos três maiores jornais brasileiros (Folha de S. Paulo, O Estado de S. Paulo e O Globo) no FB. Assim, observaram-se: 1) intensidade do debate, 2) postura do comentador (reciprocidade), 3) justificativa dos comentários e 4) reflexividade em 610.660 comentários. Dentre os principais resultados, pode-se destacar predominância de comentários monológicos e com baixa justificação. Todavia, o FB pode ser considerado um espaço de persuasão, o que predominou nos comentários.

Palavras-chave: debate público; Facebook; eleições; interação online; jornais

\section{Abstract}

The electoral debate on Facebook: comments from the audience on journalistic posts in the 2014 Brazilian presidential election

Interactive experiences online have been stimulating the development of public debate. Facebook, for example, has attracted citizens and institutions, as well as communication enterprises that see in this tool an opportunity for greater interaction with an audience. This paper identifies the characteristics of the debate among audiences in the official Facebook pages of the three main Brazilian newspapers (Folha de S.Paulo, O Estado de S.Paulo e O Globo) on the 2014 presidential election. Therefore, we have observed in 610.660 comments: 1) the debate's intensity over time; 2) the commentator's position (reciprocity); 3) justification; and 4) reflexivity. Among our main findings, one might highlight the predominance of monologues and the low level of justification. However, Facebook can be considered a space for persuasion, which prevailed in the comments.

Keywords: public debate; Facebook; elections; online interaction; newspapers

\section{Resumen}

Debate político-electoral en Facebook: los comentarios del público en posts de noticias en la elección presidencial de 2014

Experiencias interactivas en espacios digitales han estimulado el desarrollo del debate público. El Facebook (FB), por ejemplo, atrae tanto a individuos como a instituciones, tales como las empresas periodísticas, que ven en esta herramienta la oportunidad de mayor contacto con la audiencia. De esta manera, este artículo investiga las características del debate público sobre la elección presidencial de 2014, a partir de los posts en las páginas oficiales de los tres mayores periódicos brasileños (Folha de S. Paulo, O Estado de S. Paulo y O Globo), en Facebook. Así, fueron observadas: 1) la intensidad del debate; 2) la postura del comentarista (reciprocidad); 3) la justificación de los comentarios; y 4) la reflexividad, en 610.660 comentarios. Entre los principales resultados, se puede destacar la predominancia de comentarios monológicos y la baja justificación. Sin embargo, FB puede ser considerado como un espacio de persuasión, que es la característica que ha predominado en los comentarios

Palabras clave: debate público; Facebook; elecciones; interacción online; periódicos 


\section{Résumé}

Le débat électoral sur Facebook: les commentaires sur les publications journalistiques à propos de l'élection présidentielle brésilienne en 2014

Des expériences interactives en ligne stimulent le développement du débat public. Le Facebook (FB), par exemple, attire l'attention des personnes et des institutions, telles que celles du journalisme, qui voient dans ce mécanisme l'opportunité d'un contact plus grand avec leur audience. Dans cette perspective, ce texte examine les caractéristiques du débat public à propos de l'élection présidentielle au Brésil, en 2014, en observant les publications sur les pages des trois plus grands journaux brésiliens sur FB (Folha de S. Paulo, O Estado de S. Paulo et O Globo). Donc, on observe: 1) I'intensité du débat; 2) le positionnement de celui qui fait les commentaires (réciprocité); 3) la justification des commentaires; et 4) la réflexivité, dans 610660 commentaires. Parmi les principaux résultats, on peut mettre en évidence la prédominance des commentaires monologiques et de faible justification. Cependant, le FB peut être considéré comme un espace de persuasion, ce qui prédominait dans les commentaires.

Mots-clés: débat public; Facebook; élection; interaction en ligne; journaux

Artigo submetido à publicação em 28 de março de 2016.

Versão final aprovada em 3 de julho de 2017. 